\title{
ВПЛИВ ФІЗИЧНОЇ РЕАБІЛІТАЦІЇ НА ЯКІСТЬ ЖИТТЯ ХВОРИХ НА ХРОНІЧНЕ ОБСТРУКТИВНЕ ЗАХВОРЮВАННЯ ЛЕГЕНЬ
}

\author{
๑І. М. Григус, Н. Є. Нестерчук, А. О. Ногас, Л. Л. Примачок, І. В. Захарченко \\ Навчально-науковий інститут охорони здоров'я, \\ Національний університет водного господарства та природокористування, м. Рівне
}

РЕЗЮМЕ. Хронічне обструктивне захворювання легень (ХОЗЛ) посідає провідне місце серед основних причин смертності й інвалідності в більшості країн світу і зумовлює значні економічні витрати на лікування та реабілітацію хворих. Проблема ХОЗЛ набула не лише медичного, а й соціально-економічного значення, оскільки захворювання впливає не тільки на життя пацієнта, порушуючи його працездатність та знижуючи якість життя, а й на членів його родини.

Мета роботи - вивчити ефективність впливу запропонованої методики фізичної реабілітації на якість життя хворих на ХОЗЛ помірного ступеня тяжкості.

Матеріал і методи. У дослідженні брали участь 78 хворих на ХОЗЛ помірного ступеня тяжкості, які методом рандомізації були поділені на дві групи. Хворі контрольної групи отримували лікування та реабілітацію за загальноприйнятою методикою, а хворі основної групи - лікування за тим самим протоколом і реабілітацію за запропонованою методикою.

Результати. Застосування стандартного лікування та фізичної реабілітації у хворих на ХОЗЛ помірного ступеня тяжкості приводить до суттєвого підвищення якості життя. За результатами фізичної реабілітації в основній групі настає статистично значимо більша динаміка зростання різниці між значеннями після і до реабілітації. Після застосування запропонованої програми фізичної реабілітації для кожного хворого ОГ на ХОЗЛ ми спостерігали підвищення загальної якості життя та стану здоров'я за рахунок збільшення показників у проблемних субсферах.

Висновки. Застосування фізичної реабілітації дозволяє значно поліпшити якість життя хворих, істотно впливаючи на психоемоційну сферу. Достовірне $(p<0,05)$ підвищення загальної якості життя і стану здоров'я хворих на ХОЗЛ помірного ступеня тяжкості жіночої статі основної групи відбулося за всіма сферами і субсферами якості життя, за винятком духовної.

КЛючОВІ СлОВА: хронічне обструктивне захворювання легень; хворі; фізична реабілітація; якість життя.

Вступ. Хронічне обструктивне захворювання легень (ХОЗЛ) посідає одне з провідних місць серед основних причин смертності й інвалідності в більшості країн світу та зумовлює значні економічні витрати на лікування хворих. Тому ця проблема набула не лише медичного, а й соціально-економічного значення. ХОЗЛ $\epsilon$ однією з основних причин легенево-серцевої недостатності $[1,14,16]$.

Захворюваність і смертність від ХОЗЛ, незважаючи на розвиток медичної науки, продовжує зростати. Тяжкість перебігу, підходи до лікування, прогноз при ХОЗЛ визначаються не тільки ступенем ураження бронхолегеневої системи, а й позалегеневими проявами захворювання та наявністю коморбідної патології $[2,12,13]$. У матеріалах GOLD підкреслюється, що в країнах, які розвиваються, прямі витрати на лікування ХОЗЛ $€$ меншими, ніж витрати, пов'язані з неможливістю пацієнта виконувати професійні обов'язки та вести звичайний спосіб життя. В ініціативі зазначається, що тяжка форма захворювання впливає не тільки на життя пацієнта, порушуючи його працездатність та знижуючи якість життя, а й на членів його родини, які мають доглядати хворого $[2,10]$.

Легенева (респіраторна) реабілітація $\epsilon$ найефективнішою терапевтичною стратегією для зменшення задишки, покращання стану здоров'я та переносимості фізичних навантажень. Основним компонентом програм легеневої реабілітації $\epsilon$ фізична реабілітація. Застосування програм фізичної реабілітації рекомендоване на усіх стадіях ХОЗЛ, допомагає збільшити силу дихальних м'язів і м'язів ніг та рук, зменшити скутість грудної клітки і задишку, покращити фізичний стан $[3,4,7,11]$.

Мета роботи - вивчити ефективність впливу запропонованої методики фізичної реабілітації на якість життя хворих на ХОЗЛ помірного ступеня тяжкості.

Матеріал і методи дослідження. Дослідження проведено на базі пульмонологічного відділення Рівненської обласної клінічної лікарні. Накопичення результатів дослідження проводили в міру поступлення пацієнтів на стаціонарне лікування. 78 хворих жіночої статі (ХОЗЛ, ІІ стадія, помірний ступінь тяжкості), середній вік яких склав $(56,34 \pm 0,97)$ років, були поділені методом рандомізації на контрольну (КГ $2(n=40))$ та основну (ОГ 2 $(n=38)$ ) групи відповідно до принципів біоетики.

Всі хворі були обстежені на початку та наприкінці дослідження, перебували під наглядом лікарів. Оцінку фізичних можливостей кожного хворого проводили з використанням загальноприйнятих тестів із навантаженням (тредміл-тесту, 6-хвилинної ходьби тощо). 
Огляди літератури, оригінальні дослідження, погляд на проблему, ювілеї

Результати й обговорення. Важливий інструмент для аналізу методів вихідного стану здоров'я та результатів лікування й реабілітації хворих на ХОЗЛ - оцінка якості життя, що є надійним, інформативним та економним методом визначення стану здоров'я як на індивідуальному, так і на груповому рівні. Традиційно зміни, які виникають у хворих на ХОЗЛ, а також ефективність їх лікування та реабілітації лікар і фізичний терапевт оцінюють на підставі динаміки скарг, об'єктивних даних, параклінічних показників. При цьому думка пацієнта залишається формальною, адже лікар і фізичний терапевт за допомогою клінічних, лабораторних та інструментальних методів не можуть визначити весь спектр змін фізичного, психічного і соціального статусу хворого та ступінь його задоволення аспектами власного життя. Незважаючи на те, що відокремлення об'єктивних та суб'єктивних критеріїв якості життя залишається дискусійним питанням, основним інструментом для кількісного визначення цього показника вважається опитувальник. Для оцінки якості життя хворих на ХОЗЛ широко використовують респіраторний опитувальник Госпіталю CB. Георгія (SGRQ), запропонований ще у 1992 році [15]. Але, оскільки він не адаптований до українських реалій, ми використали українську версію опитувальника якості життя Всесвітньої організації охорони здоров'я (ВООЗЯЖ-100), призначену для оцінки якості життя дорослої популяції населення України [8]. Цей опитувальник відповідає всім міжнародним вимогам до подібних опитувальників, він універсальний, бо охоплює всі параметри здоров'я, рекомендується для визначення ефективності медичних і соціальних програм в Україні, відповідно до міжнародних стандартів оцінки якості життя населення.

Для вивчення загальної якості життя і стану здоров'я хворих на ХОЗЛ ми застосовували українську версію методики оцінки якості життя, що включає 100 питань, по 4 питання для кожної із 24 субсфер, а також 4 "глобальних питання" для оцінки загальної якості життя і стану здоров'я. Вивчали показники фізичної, психологічної сфер, рівня незалежності, соціальних стосунків, навколишнього середовища і духовної сфери у балах [8].

На тлі медикаментозної терапії, яка призначалася, згідно з нормативним документом, відповідно до ступеня тяжкості хвороби, проводилася фізична реабілітація [9]. Хворі контрольних груп проходили реабілітацію згідно з рекомендаціями нормативного документа МОЗ України.

Запропонована технологія фізичної реабілітації застосовувалася пацієнтами основної групи і передбачала урахування функціонального стану хворих $[5,6]$. Тривалість фізичної реабілітації в се- редньому становила 30 днів і включала стаціонарний та поліклінічний етапи.

За допомогою методики оцінки якості життя ми визначили у кожного хворого рівень якості життя на початку й наприкінці дослідження, щоби прослідкувати за змінами та оцінити ефективність проведених заходів.

На початку дослідження низький середній вихідний рівень загальної якості життя і стану здоров'я ми констатували у хворих жіночої статі обох груп. У хворих КГ 2 він складав $(47,77 \pm 0,51)$ балів, у жінок ОГ 2 - $(49,39 \pm 0,51)$ балів. Показники окремих сфер вивчення у хворих КГ 2 були наступними: сфера I (фізична сфера) - $(6,46 \pm 0,10)$, сфера II (психологічна сфера) - $(9,03 \pm 0,90)$, сфера III (рівень незалежності) - $(6,01 \pm 0,10)$, сфера IV (соціальні стосунки) - $(8,01 \pm 0,13)$, сфера V (навколишнє середовище) - $(7,92 \pm 0,08)$, сфера VI (духовна сфера) - $(10,35 \pm 0,27)$ балів.

За окремими сферами вивчення вихідний рівень загальної якості життя і стану здоров'я хворих жіночої статі ОГ 2 складав: сфера I (фізична

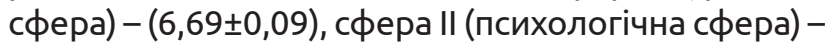
$(9,24 \pm 0,11)$, сфера III (рівень незалежності) - $(6,01 \pm$ $0,11)$, сфера IV (соціальні стосунки) - $(8,11 \pm 0,12)$, сфера V (навколишнє середовище) - $(7,99 \pm 0,08)$, сфера VI (духовна сфера) - $(11,34 \pm 0,29)$ балів. Зниження загальної якості життя хворих відбулося за рахунок негативного впливу захворювання на всі субсфери життя людини.

Наприкінці дослідження у хворих жіночої статі КГ 2 середній рівень загальної якості життя і стану здоров'я дещо підвищився і складав $(48,06 \pm$ $0,45)$ балів. Окремі показники сфер вивчення у них були: сфера I (фізична сфера) - $(6,58 \pm 0,09)$, сфера II (психологічна сфера) - $(9,04 \pm 0,08)$, сфера III (рівень незалежності) - $(6,07 \pm 0,09)$, сфера IV (соціальні стосунки) - $(8,08 \pm 0,11)$, сфера V (навколишнє середовище) - $(7,94 \pm 0,07)$, сфера VI (духовна сфера) - $(10,35 \pm 0,27)$ балів.

За окремими сферами вивчення рівень загальної якості життя і стану здоров'я хворих жіночої статі ОГ 2 суттєво зріс: сфера I (фізична сфера) $(9,82 \pm 0,07)(p<0,05)$, сфера II (психологічна сфера) $(10,53 \pm 0,09)(p<0,05)$, сфера III (рівень незалежності) - $(8,15 \pm 0,09)(p<0,05)$, сфера IV (соціальні стосунки) - $(9,20 \pm 0,10)(p<0,05)$, сфера V (навколишнє середовище) - $(8,52 \pm 0,08)(p<0,05)$, сфера VI (духовна сфера) - $(11,74 \pm 0,21)$ балів - незначно. Середній рівень загальної якості життя і стану здоров'я хворих на ХОЗЛ помірного ступеня тяжкості жіночої статі ОГ 2 підвищився до $(57,96 \pm 0,28)(p<0,05)$ балів. Достовірне підвищення загальної якості життя і стану здоров'я хворих жіночої статі ОГ відбулося за всіма сферами і субсферами якості життя, за винятком духовної. 
Огляди літератури, оригінальні дослідження, погляд на проблему, ювілеї

Загальна якість життя кожної хворої на ХОЗЛ обох груп у процесі дослідження відображена на рисунку 1.

Із наведеного на рисунку 1 видно, що на початку дослідження рівень загальної якості життя у хворих жіночої статі обох груп був приблизно однаковим. Аналізуючи результати анкетування хворих на ХОЗЛ щодо визначення загальної якості життя і стану здоров'я на початку дослідження, ми бачимо, порівнюючи їх із середніми даними здорового населення, що у хворих КГ 2 та ОГ 2 знижені показники фізичної сфери, рівня незалежності та соціальних стосунків. Найнижчі показники були отримані в наступних субсферах: дискомфорт, здатність виконувати повсякденні справи, працездатність, залежність від медикаментів і лікування, медична і соціальна допомога, можливість для відпочинку/дозвілля та транспорт, що вимагає відповідного спрямування реабілітації.

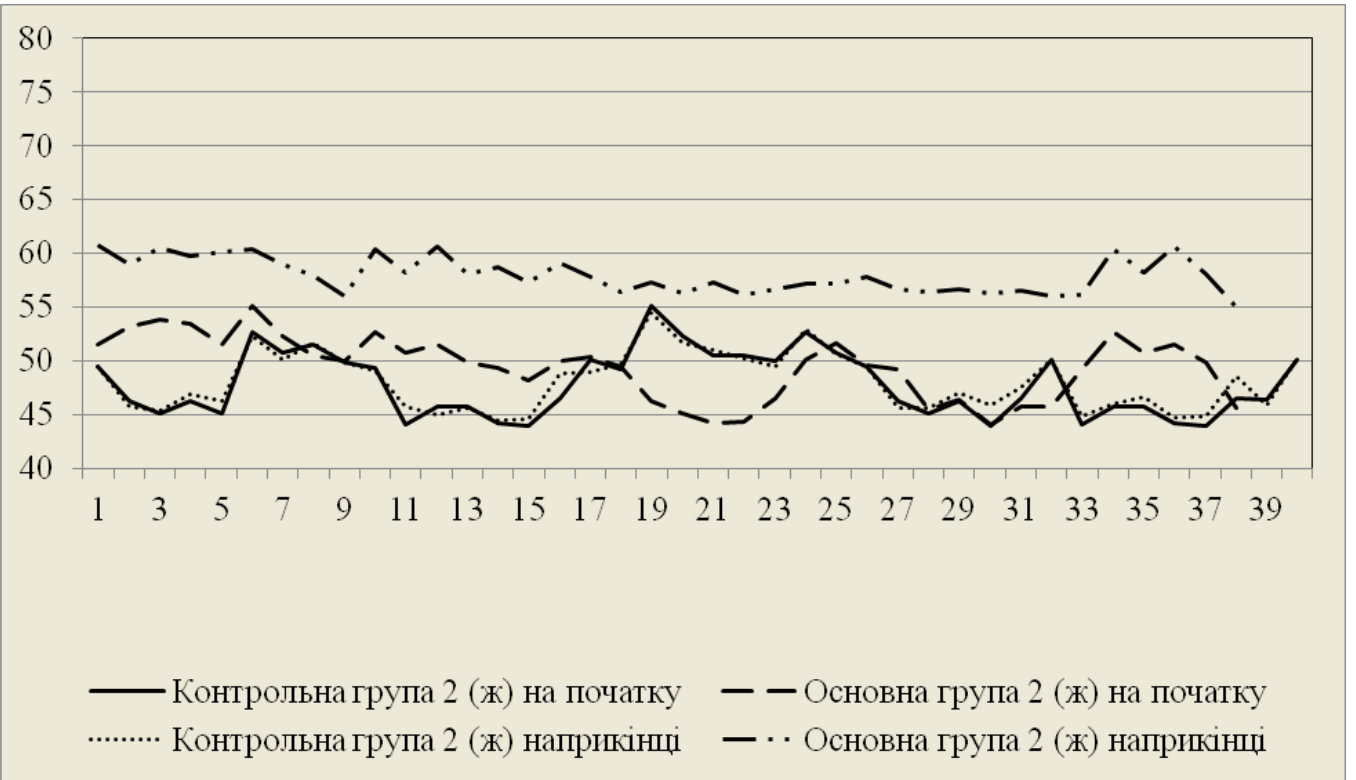

Рис. 1. Загальна якість життя і стан здоров'я хворих на хронічне обструктивне захворювання жіночої статі у процесі дослідження.

Після застосування запропонованої програми фізичної реабілітації для кожної хворої на ХОЗЛ ОГ ми спостерігали підвищення загальної якості життя та стану здоров'я за рахунок збільшення показників у проблемних субсферах. Незначно підвищилися тільки показники духовної сфери. Ухворих КГ не відмічено істотних змін загальної якості життя та стану здоров'я.

Висновки. Наприкінці дослідження хворі основної групи відмітили зменшення дискомфорту, залежності від медикаментів, підвищення мобільності, збільшення життєвої активності, працездатності, здатності до виконання повсякденних справ, зменшення стомлюваності, покращення сну, мислення, а також поліпшення особистих вза- $\epsilon м и н$. Достовірне $(p<0,05)$ підвищення загальної якості життя і стану здоров'я хворих на ХОЗЛ помірного ступеня тяжкості жіночої статі основної групи наприкінці дослідження відбулося за всіма сферами і субсферами якості життя, за винятком духовної. Застосування запропонованих програм фізичної реабілітації дозволяє поліпшити не тільки основні клінічні особливості перебігу хвороби, досягти поліпшення і стабілізації функціональних показників, а й значно підвищити якість життя хворих, істотно впливаючи на психоемоційну сферу.

Перспективи подальших досліджень вбачаємо в аналізі комплексного впливу запропонованих програм фізичної реабілітації на організм хворих в цілому.

\section{ЛІТЕРАТУРА}

1. Бронхообструктивні захворювання у дорослих осіб: етіологія, патогенез, класифікація, діагностика, лікування: навчальний посібник / за редакцією Ю. І. Фещенка. - К., 2015. - 150 с.

2. Глобальная стратегия диагностики, лечения и профилактики хронической обструктивной болезни легких (пересмотр 2014 г.) / пер. с англ.; под ред. А. С. Белевского. - М. : Российское респираторное общество, 2014. - 92 с.

3. Григус І. М. Покращання функції зовнішнього дихання у хворих на інтермітуючу бронхіальну астму / І. М. Григус // Досягнення біології та медицини, 2011. № 1 (17). - C. 18-21. 
Огляди літератури, оригінальні дослідження, погляд на проблему, ювілеї

4. Григус І. М. Фізична реабілітація в пульмонології : навч. посібник / І. М. Григус. - Рівне : НУВГП, 2015. 258 c.

5. Григус І. М. Фізична реабілітація при захворюваннях дихальної системи. - Вид. 2-ге переробл. / І. М. Григус. - Рівне : [6. в.], 2009. - 112 с.

6. Майструк М. Методичні аспекти проведення фізичної реабілітації хворих на хронічне обструктивне захворювання легень / М. Майструк // Фізичне виховання, спорт і культура здоров'я у сучасному суспільстві : 36. наук. пр. - Луцьк, 2015. - № 3 (31). - С. 216-220.

7. Малявин А. Г. Респираторная медицинская реабилитация. Практическое руководство для врачей / А. Г. Малявин. - М. : Практическая медицина, 2006. - 416 с.

8. Методика оцінки якості життя / Всесвітня організація охорони здоров'я: Українська версія (Рекомендації по використанню) / за наук. ред. д.м.н. С. В. Пхіденка. - Дніпропетровськ : Пороги, 2001. - 58 с.

9. Наказ МОЗ України № 555 від 27.06.2013 р. Хронічне обструктивне захворювання легень. Адаптована клінічна настанова, заснована на доказах. Уніфікований клінічний протокол первинної, вторинної (спеціалізованої), третинної (високоспеціалізованої) медичної допомоги та медичної реабілітації.

10. Global Strategy for the Diagnosis, Management, and Prevention of Chronic Obstructive Pulmonary Disease (2017 Report). - Available at: http://goldcopd.org/gold2017-global-strategy-diagnosis-management-preventioncopd.

11. Grygus I. The role of physical activity in the rehabilitation of patients suffering from mild persistent bronchial asthma / I. Grygus // Physical Activity Review. - 2017.Vol. 5. - P. 155-166.

12. Grygus I. Fizjoterapia w pulmonologii. Physiotherapy in pulmonology / I. Grygus, M. Kochanowicz, M. Mieszkowska. - Kraków, KAFM. - 2016. - 160 p.

13. Grygus I. Effect of physical therapy on respiratory function in patients with chronic obstructive pulmonary disease / I. Grygus, M. Maistruk, W. Zukow // Collegium Antropologicum. - 2017. - Vol. 41 (3). - P. 255-261.

14. Hakamy Ali. The effect of pulmonary rehabilitation on mortality, balance, and risk of fall in stable patients with chronic obstructive pulmonary disease: A systematic review / Hakamy Ali, Charlotte E. Bolton, Tricia M. McKeever // Chronic Respiratory Disease. - 2017. - Vol. 14 (1). - P. 54-62.

15. Jones P. W. St. George's respiratory questionnaire for COPD patients manual / P. W. Jones, Y. Forde. - St. George`s University of London. - 2008. - P. 15.

16. Kerwin E. A. New alphabet for COPD care /E. A. Kerwin // Europ. Respir. J. -2016. - Vol. 48. - P. 972-975.

\section{REFERENCES}

1. Feshchenko, Yu.I. (2015). Bronkhoobstruktyvni zakhvoriuvannia u doroslykh osib: etiolohiia, patohenez, klasyfikatsiia, diahnostyka, likuvannia. Navchalnyi posibnyk [Bronchoobstructive diseases in adults: etiology, pathogenesis, classification, diagnosis, treatment: a tutorial]. Kyiv. [in Ukrainian].

2. Belevskiy, A.S. (Ed.). (2014). Globalnaya strategiya diagnostiki, lecheniya i profilaktiki khronicheskoy obstruktivnoy bolezni legkikh (peresmotr 2014 g.) / per. s angl. [Global strategy for the diagnosis, treatment and prevention of chronic obstructive pulmonary disease (revision 2014) / trans. from English]. Moscow: Rossiyskoe respiratornoye obshchestvo [in Russian].

3. Hryhus, I.M. (2011). Pokrashchennia funktsii zovnishnoho dykhannia u khvorykh na intermituiuchu bronkhialnu astmu [Improvement of the function of external respiration in patients with intermittent bronchial asthma]. Dosiahnennia biolohii ta medytsyny - Achievements in Biology and Medicine, 1 (17), 18-21 [in Ukrainian].

4. Hryhus, I.M. (2015). Fizychna reabilitatsiia v pulmonolohii: navch. Posibnyk [Physical rehabilitation in pulmonology: Manual]. Rivne: NUVHP [in Ukrainian].

5. Hryhus, I.M. (2009). Fizychna reabilitatsiia pry zakhvoriuvanniakh dykhalnoi systemy. Vyd. 2-he pererobl. [Physical rehabilitation for diseases of the respiratory system. $2^{\text {nd }}$ publication, revised]. Rivne [in Ukrainian].

6. Maistruk M. Metodychni aspekty provedennia fizychnoi reabilitatsii khvorykh na khronichne obstruktyvne zakhvoriuvannia lehen [Methodical aspects of physical rehabilitation of patients with chronic obstructive pulmonary disease]. Fizychne vykhovannia, sport i kultura zdorovia u suchasnomu suspilstvi: zb. nauk. pr. - Physical Training, Sport and Culture of Health in Modern Society. Lutsk [in Ukrainian].

7. Malyavin, A.G. (2006). Respiratornaya meditsinskaya reabilitatsiya. Prakticheskoye rukovodstvo dlya vra-

chey [Respiratory medical rehabilitation. A practical guide for doctors]. Moscow: Prakticheskaya meditsina [in Russian].

8. Pkhidenko, S.V. (2001). Metodyka otsinky yakosti zhyttia / Vsesvitnia orhanizatsiia okhorony zdorovia: Ukrainska versiia (Rekomendatsii po vykorystanniu) [Methodology for assessing the quality of life / World Health Organization: Ukrainian version (Recommendations for use)]. Dnipropetrovsk: Porohy [in Ukrainian].

9. Nakaz MOZ Ukrainy № 555 vid 27.06.2013 г. Khronichne obstruktyvne zakhvoriuvannia lehen. Adaptovana klinichna nastanova, zasnovana na dokazakh. Unifikovanyi klinichnyi protokol pervynnoi, vtorynnoi (spetsializovanoi), tretynnoi (vysokospetsializovanoi) medychnoi dopomohy ta medychnoi reabilitatsii [Order of the Ministry of Health of Ukraine No. 555 dated June 27, 2013 Chronic Obstructive Pulmonary Disease. Adapted clinical guideline based on evidence. Unified clinical protocol of primary, secondary (specialized), tertiary (highly specialized) medical care and medical rehabilitation]. [in Ukrainian].

10. Global Strategy for the Diagnosis, Management, and Prevention of Chronic Obstructive Pulmonary Disease (2017 Report). Retrieved from: http://goldcopd.org/gold2017-global-strategy-diagnosis-management-preventioncopd.

11. Grygus, I. (2017). The role of physical activity in the rehabilitation of patients suffering from mild persistent bronchial asthma. Physical Activity Review, 5, 155-166.

12. Grygus, I., Kochanowicz, M., \& Mieszkowska, M. (2016). Fizjoterapia w pulmonologii. Physiotherapy in Pulmonology. Kraków, KAFM.

13. Grygus, I., Maistruk, M., \& Zukow, W. (2017). Effect of physical therapy on respiratory function in patients with chronic obstructive pulmonary disease. Collegium Antropologicum, 41 (3), 255-261. 
Огляди літератури, оригінальні дослідження, погляд на проблему, ювілеї

14. Hakamy, Ali, Charlotte E. Bolton, Tricia M. McKeever (2017). The effect of pulmonary rehabilitation on mortality, balance, and risk of fall in stable patients with chronic obstructive pulmonary disease: A systematic review. Chronic Respiratory Disease, 14 (1), 54-62.
15. Jones, P.W., \& Forde, Y. (2008). St. George's respiratory questionnaire for COPD patients manual. St. George`s University of London.

16. Kerwin, E.A. (2016). New alphabet for COPD care. Europ. Respir. J., 48, 972-975.

\title{
ВЛИЯНИЕ ПРОВЕДЕННОЙ ФИЗИЧЕСКОЙ РЕАБИЛИТАЦИИ НА КАЧЕСТВО ЖИЗНИ БОЛЬНЫХ ХРОНИЧЕСКОЙ ОБСТРУКТИВНОЙ БОЛЕЗНЬЮ ЛЕГКИХ
}

\author{
ОИ. М. Григус, Н. Е. Нестечук, А. А. Ногас, Л. Л. Примачок, И. В. Захарченко \\ учебно-научный институт здравоохранения, \\ Национальный университет водного хозяйства и природопользования, г. Ровно
}

РЕЗЮМЕ. Хроническая обструктивная болезнь легких (ХОБЛ) занимает ведущее место среди основных причин смертности и инвалидности в большинстве стран мира и вызывает значительные экономические затраты на лечение и реабилитацию больных. Проблема ХОБЛ приобрела не только медицинское, но и социально-экономическое значение, так как заболевание влияет не только на жизнь пациента, нарушая его работоспособность и снижая качество жизни, но и на членов его семьи.

Цель работы - изучить эффективность влияния предложенной методики физической реабилитации на качество жизни больных ХОБЛ средней степени тяжести.

Материал и методы. В исследовании участвовали 78 больных ХОБЛ средней степени тяжести, которые методом рандомизации были поделены на две группы. Больные контрольной группы проходили лечение и реабилитацию по общепринятой методике, а больные основной группы - лечение согласно тому же протоколу и реабилитацию по предложенной методике.

Результаты. Применение стандартного лечения и физической реабилитации у больных ХОБЛ средней степени тяжести приводит к существенному повышению качества жизни. По результатам физической реабилитации в основной группе наступает статистически значимо большая динамика роста разницы между значениями после и до реабилитации. После применения предложенной программы физической реабилитации для каждого больного ОГ ХОБЛ мы наблюдали повышение общего качества жизни и состояния здоровья за счет увеличения показателей в проблемных субсферах.

Выводы. Применение физической реабилитации позволяет значительно повысить качество жизни больных, существенно влияя на психоэмоциональную сферу. Достоверное $(p<0,05)$ повышение общего качества жизни и состояния здоровья больных ХОБЛ средней степени тяжести женского пола основной группы произошло по всем сферам и субсферам качества жизни, за исключением духовной.

КЛЮчЕВЫЕ сЛОВА: хроническая обструктивная болезнь легких; больные; физическая реабилитация; качество жизни.

\section{INFLUENCE OF THE CONDUCTED PHYSICAL REHABILITATION ON QUALITY OF LIFE IN PATIENTS WITH COPD}

\author{
OI. M. Grygus, N. E. Nesterchuk, A. O. Nogas, L. L. Prymachok, I. V. Zacharchenko \\ Institute of Health, National University of Water and Environmental Engineering, Rivne
}

SUMMARY. Chronic obstructive pulmonary disease (COPD) is one of the leading causes of death and disability in most countries of the world and causes significant economic costs for the treatment and rehabilitation of patients. The problem of COPD has acquired not only medical, but also socio-economic importance, since the disease affects not only the patient's life, disrupting his working capacity and reducing the quality of life, but also his family members.

The aim of the work - to study the effectiveness of the influence of the proposed method of physical rehabilitation on the quality of life of patients with moderate COPD.

Material and Methods. The study involved 78 patients with COPD of moderate severity, which were divided into two groups by randomization. Patients of the control group were treated and rehabilitated according to the generally accepted method, and patients of the main group received treatment according to the same protocol and rehabilitation according to the proposed method.

Results. The use of standard treatment and physical rehabilitation in patients with moderate COPD leads to a significant improvement in the quality of life. According to the results of physical rehabilitation in the main group, there is a statistically significantly greater growth dynamics of the difference between the values after and before rehabilitation. After the application of the proposed physical rehabilitation program for each patient with COPD, we observed an increase in the overall quality of life and health due to an increase in indicators in problem subspheres.

Conclusions. The use of physical rehabilitation can significantly improve the quality of life of patients, significantly affecting the psycho-emotional sphere. A significant $(p<0.05)$ increase in the overall quality of life and the state of health of patients with COPD of moderate severity of the female sex of the main group occurred in all spheres and the subsphere of the quality of life, except for the spiritual.

KEY WORDS: chronic obstructive pulmonary disease; patients; physical rehabilitation; quality of life. 